$\mathrm{DE}$

M E D I C I N A

T R O P I C A L

$\mathrm{DE}$

S ÃO PAULO

JOURNAL OF THE SÃO PAULO INSTITUTE OF TROPICAL MEDICINE

'Universidad Cooperativa de Colombia, Grupo de Investigación en Ciencias Animales, Bucaramanga, Colombia

2Universidad de Santander, Facultad de Ciencias de la Salud, Programa de Bacteriología y Laboratorio Clínico, Grupo de Investigación en Manejo Clínico, Bucaramanga, Colombia

Correspondence to: Julian Ruiz-Saenz Universidad Cooperativa de Colombia, Calle 30A \# 33-51, Bucaramanga, Colombia Tel: +5776854500 , ext 7072

E-mail: julian.ruizs@campusucc.edu.co

Received: 24 January 2019

Accepted: 26 April 2019

\section{Prevalence and molecular typing of rotavirus in children with acute diarrhoea in Northeastern Colombia}

\author{
Marlen Martinez-Gutierrez ${ }^{(1)}$, Victor Arcila-Quiceno ${ }^{\left({ }^{\circledR} 1\right.}$, \\ Juanita Trejos-Suarez ${ }^{\circledR}$, Julian Ruiz-Saenz ${ }^{(1)}$
}

\section{ABSTRACT}

After the introduction of the rotavirus vaccine, the number of rotavirus-associated deaths and the predicted annual rotavirus detection rate had slightly declined worldwide. Taking in account that in Colombia, Rotarix vaccine was introduced in 2009, the purpose of this study was to evaluate the presence of rotavirus $\mathrm{A}$ in children under five years who were treated for acute diarrhoea in Bucaramanga, Colombia and, moreover, to determine the genotypes of rotavirus present in those children. We performed an analytical cross-sectional study of rotavirus A in faecal samples from children up to five years of age. Stool samples were screened for rotavirus A using a lateral-flow immunochromatographic assay and confirmed using a VP6 sandwich ELISA. Genotyping of rotavirus A-positive samples was performed by PCR and sequencing of VP7 and VP4 genes. The overall prevalence of rotavirus was $30.53 \%$ (95\% confidence interval [CI] 21.2 - 39.7). Most of the children with rotavirus $(86.2 \%)$ had received two doses of the rotavirus vaccine. G3 strains accounted for the vast majority of cases (82.8\%), followed by G12 strains (13.8\%) and G3/G9 coinfections (3.4\%). Among the P genotypes, P[8] was the most prevalent (69\%), followed by P[9] (31\%). The most common $\mathrm{G}[\mathrm{P}]$ genotype combination was G3P[8], followed by G3P[9]. The main finding in this study was that rotavirus, in a Colombian region, is still an important pathogen in children under five years old, previously vaccinated. The results showed that different factors, such as kindergarten attendance, could explain the epidemiology and transmission of rotavirus in Bucaramanga.

KEYWORDS: Acute diarrhoea. Colombia. Molecular characterization. Post-vaccination. Rotavirus

\section{INTRODUCTION}

Acute diarrhoea (defined by the occurrence of three or more loose, liquid, or watery stools or at least one bloody loose stool in a $24 \mathrm{~h}$ period $^{1}$ ) is one of the most common diseases in infants and young children in both, developed and developing countries ${ }^{2}$. The incidence of diarrhoea in African, Latin American and Asian countries in children under 5 years of age has been estimated to be over one billion, with approximately 3.3 million deaths per year ${ }^{3}$. Rotavirus A is considered one of the most important causes of severe acute gastroenteritis in infants and young children in both, developed and developing countries ${ }^{4}$. In the pre-vaccination era, estimates indicated that rotavirus A caused 111 million episodes of diarrhoea requiring only home care, 25 million clinic visits, 2 million hospitalizations, and $325,000-592,000$ deaths (a median of 440,000 deaths) in children under 5 years of age (per year), primarily in developing countries ${ }^{5}$. 
In 2009, the World Health Organization (WHO) recommended the global introduction of rotavirus vaccines in national immunization programs ${ }^{6}$. Post-vaccine introduction analysis showed that the number of rotavirus A-associated deaths in children under 5 years of age declined globally from 528,000 (95\% confidence interval 465,000-591,000) in 2000 to 215,000 (range, 197,000-233,000) in 2013, and the predicted annual rotavirus detection rate declined slightly over time from $42.5 \%$ to $37.3 \%$, globally ${ }^{7}$. In the most recent analysis, rotavirus was responsible for an estimated 128,500 deaths (95\% confidence interval 104,500-155,600) among children younger than 5 years throughout the world and has been responsible for more than 258 million episodes of diarrhoea among children (95\% interval 193 -341 million), concluding that rotavirus-associated mortality has decreased markedly over time in part because of the introduction of the rotavirus vaccine $e^{8}$. Before the introduction of rotavirus vaccine in Latin America, more than 15,000 deaths annually were related to rotavirus A infections; however, recent reports from Latin American countries have shown a decline in mortality due to diarrhoea after the rotavirus vaccine was implemented ${ }^{9,10}$. For example, an in-hospital surveillance system indicated that in Colombia (before the introduction of vaccination, in January 2009) the rotavirus infection was the cause of approximately $50 \%$ of the hospitalizations due to diarrhoea ${ }^{11}$. Specifically in Bucaramanga City (the Northeastern region of Colombia), prior to vaccine introduction, rotavirus A was the main cause of diarrhoeal disease in children under five years who consulted emergency services, accounting for $44.4 \%$ (95\% confidence interval [CI] 37.1-52.0) of the cases ${ }^{12}$. However, since the introduction of vaccination, the presence of rotavirus $\mathrm{A}$ as a pathogen in children under five years, consulting for acute diarrhoea has not been evaluated. Therefore, the purpose of this study was to evaluate the presence of rotavirus A in children under five years who were treated for acute diarrhoea in Bucaramanga, Colombia. In addition, we determined the various genotypes of rotavirus present in those children.

\section{MATERIALS AND METHODS}

\section{Ethics statement}

This study was conducted in accordance with the Declaration of Helsinki. The Research and Ethics Committees of the Universidad Cooperativa de Colombia (Act $\mathrm{N}^{\circ}$ 6, July 7, 2014) and of the Bucaramanga Institute of Health - ISABU (Rad No 002537, March $18,2015)$ approved this study. We applied the STROBE (STrengthening the Reporting of OBservational studies in Epidemiology) procedures for the observational studies.
The samples and results were identified and analysed anonymously. All caretakers of the children enrolled who agreed to participate signed a written consent form approved by the ethics board. After a caretaker had signed the written consent form to participate in the study, nursing personnel used a standardized data collection form to obtain critical information, such as the place of residence, age, sex, feeding history, presence and duration of fever and/or vomiting, consistency and frequency of stool, and diarrhoea duration in the last 24-48 h. Participants were asked if there was any history of a neighbour with diarrhoea and if they had contact with farms or farm animals, as well as about the caretakers' professions, among other questions. Vaccine coverage was asked and confirmed by the review of the children's vaccination cards.

\section{Study settings}

\section{Study design and population}

We developed an analytical cross-sectional study on the presence of rotavirus A in faecal samples of children up to 5 years of age who presented with acute gastroenteritis.

\section{Case definition}

A case of acute diarrhoea was defined by the occurrence of three or more loose, liquid, or watery stools or at least one bloody loose stool in a $24 \mathrm{~h}$ period ${ }^{1}$.

\section{Sampling}

The samples (95 stool samples) were collected in two public hospitals belonging to the Bucaramanga Institute of Health - ISABU in the Northeastern region of Colombia (Figure 1).

\section{Study period}

The samples were collected between June 2015 and January 2016, which was determined to be sufficient to provide a confidence level of $95 \%$, a margin of error of $10 \%$, and an expected prevalence of $44 \%$.

\section{Laboratory methods}

We used immunological tests to identify and confirm faecal samples positivity to rotavirus and molecular analysis to classify the circulating genotypes, as we describe below.

Identification of rotavirus-positive samples by immunological tests

As soon as the stool samples arrived at the laboratory, they were split into three aliquots and immediately frozen at $-70{ }^{\circ} \mathrm{C}$. According to the $\mathrm{WHO}$ recommendations, all stool 


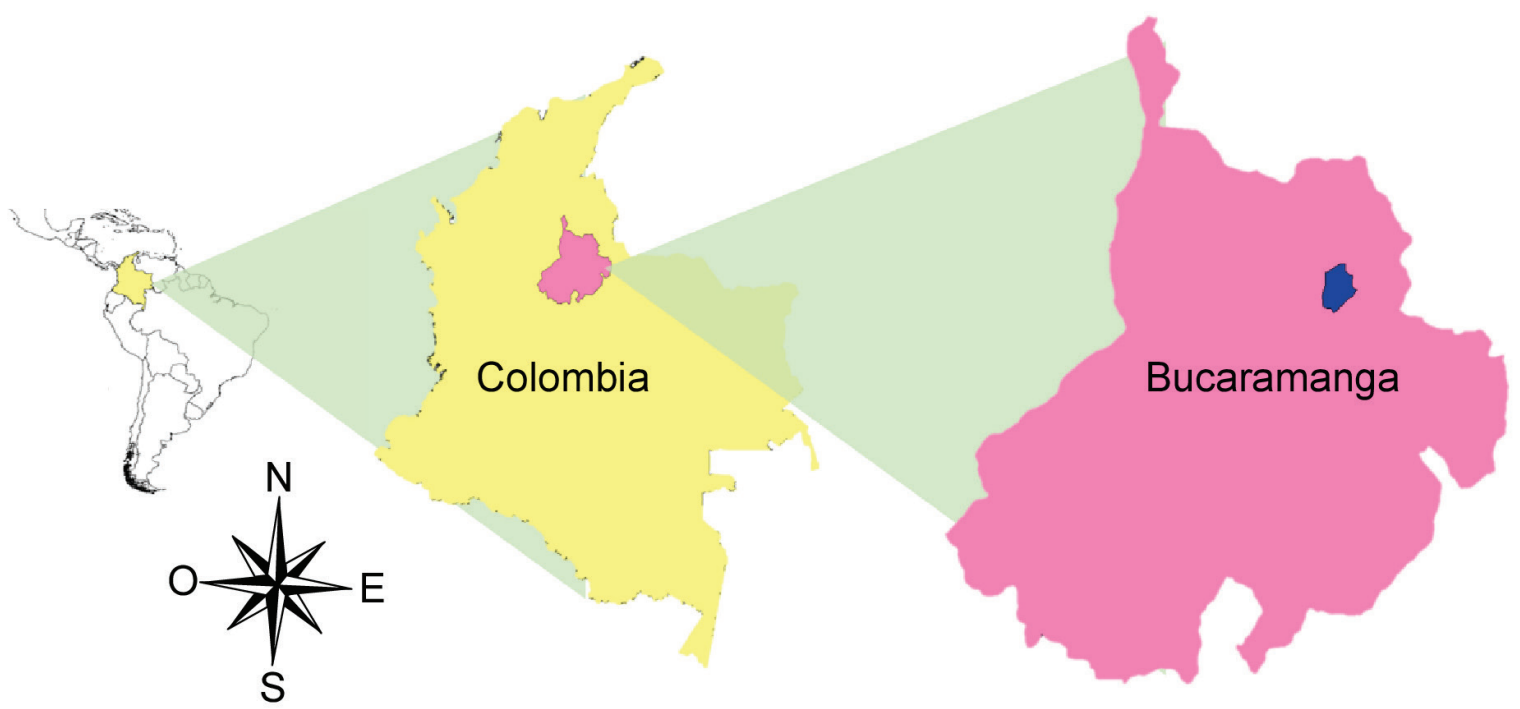

Figure 1 - Geographical location of the sampling site in Colombia. The pink area denotes Santander Province, and the blue area denotes Bucaramanga City. The map was created using the DIVA-GIS software, version 7.5.0 for Windows ${ }^{\mathrm{TM}}$.

samples were screened for rotavirus A using a commercially available lateral-flow immunochromatographic assay (The Rida Quick Rotavirus/Adenovirus Combi, r-Biopharm, Darmstadt, Germany) that used labelled monoclonal antibodies against rota- and adenoviruses surface antigens. Positive samples were confirmed using a second aliquot of the stool in an ELISA assay that employed monoclonal antibodies for rotavirus group-specific antigen (VP6) using a sandwich-type method (Ridascreen ELISA tests of r-Biopharm). Both methods were performed according to the manufacturer's instructions.

\section{Identification of circulating genotypes by molecular analysis}

\section{RNA extraction}

Stool suspensions (10\%) were prepared in $0.01 \mathrm{M}$ phosphate-buffered saline (PBS) (pH 7.2), vortexed and centrifuged. The supernatant was filtered using a $0.22-\mu \mathrm{m}$ filter and transferred to a sterile centrifuge tube. The total RNA was extracted from $140 \mu \mathrm{L}$ of the faecal suspension using the QIAamp Viral RNA extraction kit (QIAGEN, Hilden, Germany) according to the manufacturer's instructions. The RNA quality and quantity were determined spectrophotometrically by using a NanoDrop ND-1000 spectrophotometer (Thermo Fisher Scientific Inc., Waltham, MA, USA) with $1 \mu \mathrm{L}$ of sample. RNA aliquots were stored at $-70{ }^{\circ} \mathrm{C}$ until used in PCR assays.

\section{Complementary DNA (cDNA) synthesis}

Synthesis of cDNA was performed using the RevertAid ${ }^{\mathrm{TM}}$ Premium First Strand cDNA Synthesis Kit (Thermo Scientific $^{\circledast}$ Glen Burnie, MD, USA) according to the manufacturer's instructions. Briefly, a denaturation mix consisting of $1 \mu \mathrm{L}(100 \mathrm{pmol} / \mu \mathrm{L})$ of random hexamers, $1 \mu \mathrm{L}$ of dNTP mix $(10 \mathrm{mM})$, and $13 \mu \mathrm{L}(0.02-4.6 \mu \mathrm{g})$ of total RNA was initially denatured at $65^{\circ} \mathrm{C}$ for $5 \mathrm{~min}$ and immediately incubated on ice. The RT mix solution contained $4 \mu \mathrm{L}$ of $5 \mathrm{X}$ RT Buffer and $1 \mu \mathrm{L}$ of RevertAid ${ }^{\mathrm{TM}}$ Premium Enzyme Mix. The RT mix was added to the denaturation mix, and reverse transcription was performed in a total volume of $20 \mu \mathrm{L}$ in a Thermal Cycler for $10 \mathrm{~min}$ at $25{ }^{\circ} \mathrm{C}$, followed by $60 \mathrm{~min}$ at $42{ }^{\circ} \mathrm{C}$. The reaction was stopped by heating to $85^{\circ} \mathrm{C}$ for $5 \mathrm{~min}$. The reaction product was stored at $-80^{\circ} \mathrm{C}$ until used.

\section{Genotyping by PCR}

Following the procedures described by the WHO Rotavirus collaborating Center in Atlanta, Georgia, USA, for rotavirus detection and characterization ${ }^{13}$, we performed the PCR based on the amplification of the VP7 and VP4 genes by using a primer set specific for each segment, followed by a second semi-nested amplification reaction using a mixture of specific primers for each genotype (i.e., specific internal primers for genotypes $\mathrm{G} 1, \mathrm{G} 2, \mathrm{G} 3, \mathrm{G} 4, \mathrm{G} 9$, and $\mathrm{G} 12$ and internal primers for genotypes $\mathrm{P} 4, \mathrm{P} 6, \mathrm{P} 8$, and P11) (Table 1). The initial amplification conditions included denaturation at $95^{\circ} \mathrm{C}$ for $15 \mathrm{~min}$ and 30 cycles, as follows: denaturation at $94{ }^{\circ} \mathrm{C}$ for $30 \mathrm{~s}$, annealing at $42{ }^{\circ} \mathrm{C}$ for $30 \mathrm{~s}$, extension at $72{ }^{\circ} \mathrm{C}$ for $1 \mathrm{~min}$, and extension at $72{ }^{\circ} \mathrm{C}$ for $7 \mathrm{~min}$. The conditions for the second amplification of $\mathrm{G}$ and $[\mathrm{P}]$ genotypes were 1 cycle of denaturation at $94{ }^{\circ} \mathrm{C}$ for $3 \mathrm{~min}$ and 30 cycles, as follows: denaturation at $94^{\circ} \mathrm{C}$ for $40 \mathrm{~s}$, annealing at $45^{\circ} \mathrm{C}$ for $30 \mathrm{~s}$, extension at $72{ }^{\circ} \mathrm{C}$ for $1 \mathrm{~min}$, and extension at $72{ }^{\circ} \mathrm{C}$ for $7 \mathrm{~min}$. The amplified DNA was visualized by TAE electrophoresis in buffer $(4 \mathrm{mmol} / \mathrm{L}$ 
Tris-acetate, $1 \mathrm{mmol} / \mathrm{L}$ EDTA pH 8.0). Electrophoresis was performed in agarose gels at $100-120 \mathrm{~V}$ for $60 \mathrm{~min}$, and the bands were observed using the EZ-VISION ${ }^{\mathrm{TM}}\left(\right.$ Amresco $^{\circledR}$ Solon, OH, USA) coupled to a UV transilluminator (Mini BIS Pro, DNR Bio Imaging. Systems, Jerusalem, Israel). The molecular weights of amplification products were estimated using a molecular weight ladder ranging from 100 to 3000 bp (GeneRuler ${ }^{\mathrm{TM}} 100$ bp Plus DNA Ladder, Thermo Scientific ${ }^{\circledR}$ ) with the DNR GelCapture ${ }^{\circledR}$ software (DNR Bio-imaging System, Ltd., Israel).

Table 1 - Primers used for PCR genotyping. The sequences are in accordance with those reported by the WHO.

\begin{tabular}{cc}
\hline Primer & Sequence (5' to 3') \\
\hline First-amplification consensus primers G \\
9con1/F & TAG CTC CTT TTA ATG TAT GG \\
9con2/R & GTA TAA AAT ACT TGC CAC CA \\
Second-amplification genotyping primers G \\
9T-1 & TCT TGT CAA AGC AAA TAA TG \\
9T-2 & GTT AGA AAT GAT TCT CCA CT \\
9T-3 & GTC CAG TTG CAG TGT AGC \\
9T-4 & GGG TCG ATG GAA AAT TCT \\
9T-9 & TAT AAA GTC CAT TGC AC \\
G12B & CCG ATG GAC GTA ACG TTG TA \\
First-amplification consensus primers P \\
con3/F & TGG CTT CGC TCA TTT ATA GAC A \\
con3/R & ATT TCG GAC CAT TTA TAA CC \\
Second amplification (including VP7-Rdeg) P \\
1T-1 \\
2T-1 \\
3T-1
\end{tabular}

\section{$G$ and P-genotyping confirmation by sequencing}

One step RT-PCR was carried out using the SuperScript ${ }^{\circledR}$ III One-Step RT-PCR System with Platinum ${ }^{\circledR}$ Taq DNAPolymerase. (Life Technologies ${ }^{\mathrm{TM}}$, Paisley, UK). Each reaction was performed by adding $12.5 \mu \mathrm{L} 2 \times$ reaction mix, $1 \mu \mathrm{L}$ of the enzyme, $1 \mu \mathrm{L}$ of primers $(10 \mu \mathrm{M})$, $0.5 \mu \mathrm{L}$ of the extracted RNA and nuclease-free water. The amplification conditions included $60{ }^{\circ} \mathrm{C}$ for $30 \mathrm{~min}$, $94{ }^{\circ} \mathrm{C}$ for 2 min followed by 45 cycles of $94^{\circ} \mathrm{C}$ for $15 \mathrm{~s}$, $55^{\circ} \mathrm{C}$ for $30 \mathrm{~s}, 68^{\circ} \mathrm{C}$ for $2 \mathrm{~min}$ and a final extension of $68{ }^{\circ} \mathrm{C}$ for $5 \mathrm{~min}$. We amplified a 1,062-bp fragment of the VP7 gene with the consensus forward primer Beg9 (5'-GGCTTTAAAAGAGAGAATTTCCGTCTGG-3') and the reverse primer End9 (5'-GGTCACATCATACAA
TTCTAATCTAAG-3') ${ }^{14}$. For the VP4 sequencing, the con3/F and con3/R amplification (Table 1) were used as the template DNA. The amplicons of RT-PCR were purified and sequenced by Macrogen Inc. (Seoul, Korea) in an ABI 3730xl automated sequencer. To confirm the G genotypes, the sequences obtained were compared with various prototype strains of each G-genotype by using BLAST $^{\mathrm{TM}}$ and the RotaC v2.0 automated genotyping tool for Group A rotaviruses.

\section{Statistical analysis}

Data were analyzed using the software Prism ${ }^{\circledR} 7.01$ for Windows ${ }^{\mathrm{TM}}$ (GraphPad Software, San Diego, CA). Descriptive statistics of the demographic data were generated. Categorical variables are summarized as frequencies and proportions, and continuous variables are summarized where appropriate as means or medians with their measures of dispersion. A bivariate analysis to compare the rotavirus-positive and -negative patient characteristics was performed using the chi-square test or the Fisher's exact test. Normality was verified using the Shapiro-Wilk test, and differences between continuous variables were calculated using the Mann-Whitney test. In all cases, $P$ values $<0.05$ were considered statistically significant.

\section{RESULTS}

Between June 2015 and January 2016, 95 faecal samples from a group of children with diarrhoea were obtained from the ISABU. The entire population was composed of children with an average age of 19 months (range, 1 to 55 months). No gender prevalence was evidenced ( $51.6 \%$ female, $48.4 \%$ male). All children enrolled in the study were admitted to the hospital presenting with signs of acute gastroenteritis and acute diarrhoea (watery [39\%], semiliquid [61\%]) and in some cases bloody stools [29.4\%]. The average number of diarrhoea episodes in the 24 hours prior to hospital admission was seven episodes (range, 4 to 15), the frequency of vomiting was reported as $75 \%$, and fever was present in $78 \%$ of the children. Clinical dehydration (defined according to the $\mathrm{WHO}^{15}$ ) was found in only $14 \%$ of the children, and $6.31 \%$ of the enrolled children required hospitalization.

Regarding vaccine coverage, $87 \%$ of the children were found to have had at least one dose of rotavirus vaccine. Most children vaccinated against rotavirus had received two doses ( $87 \%$ of the total vaccinated children), while only $13 \%$ had received one dose. Among the children under 9 months of age, $31.45 \%$ had received one dose of rotavirus vaccine and $68.6 \%$ had received two doses of rotavirus vaccine. 
The overall prevalence of rotavirus A measured by the immunochromatographic was $30.53 \%$ (95\% CI, 21.2-39.7\%). Moreover, all positive samples were confirmed by ELISA with a concordance of $100 \%$ between these two tests. . Most of the rotavirus-positive children had received two doses of rotavirus vaccine $(86.2 \%), 6.9 \%$ had received at least one dose and $6.9 \%$ did not have a vaccination card to confirm rotavirus vaccination.

Among the rotavirus A-infected children, diarrhoea, fever and vomiting were the most common symptoms, present in $100 \%, 86 \%$ and $79 \%$ of the rotavirus-positive children, respectively. Dehydration among the rotaviruspositive children was present in $24 \%$ of the patients, and $14 \%$ of these children required hospitalization. A significantly greater number of diarrhoea episodes were present in the children who were positive for rotavirus ( $7.857 \pm 0.574)$ compared to the rotavirus-negative children (6.6 \pm 0.2956$)$ with a $p$ value 0.0375 .

The chi-square test was used to compare the rotaviruspositive and -negative children enrolled in the study according to different factors. We did not find any difference between rotavirus-positive and rotavirus-negative children when they were compared by gender, fever, vomiting and hospitalization. Factors associated with rotavirus positivity are shown in Table 2. Kindergarten care $(p=0.0108)$ was significantly associated with rotavirus diarrhoea, and no association was found with breastfeeding, living with animals or contact with adults who had diarrhoea.
An examination of the distribution of cases by age indicated that most of the rotavirus A-positive cases (51.7\%) occurred in infants aged between 12 and 36 months, whereas only $17.23 \%$ of cases occurred during the first 12 months of life (Figure 2A and 2B). None of the children under 6 months of age were confirmed as rotavirus A-positive. When we compared the ages of rotavirus-positive and -negative children, we found that the rotavirus-positive children were significantly older than the rotavirus-negative children (24.83 $\pm 2.331, p=0.0009)$, as shown in Figure 2C and Table 2. However, we did not find any statistical difference when we compared each of the individual age groups between rotavirus A-positive and negative cases (data no shown).

\section{Molecular confirmation of the rotavirus circulation}

All ELISA rotavirus-positive samples were confirmed and genotyped by molecular techniques via amplification of the VP7 and VP4 genes using specific primers for each segment, followed by a second semi-nested amplification using a mixture of specific primers for each genotype (Table 1). Due to the fact that some G-types could not be typed by this technique, all $\mathrm{G}$ samples were re-amplified by using consensus VP7 primers and then sequenced.

Among the G-types, G3 strains (82.8\%) accounted for the vast majority of cases, followed by the G12 strains (13.8\%) and G3/G9 coinfections (3.4\%). Among

Table 2 - Characteristics of the enrolled children with acute diarrhoea according to rotavirus positivity or negativity.

\begin{tabular}{lccc}
\hline & $\begin{array}{c}\text { Rotavirus-positive } \\
(\mathrm{N}=29)\end{array}$ & $\begin{array}{c}\text { Rotavirus-negative } \\
(\mathrm{N}=66)\end{array}$ & P value \\
\hline Factor & & & \\
$\quad$ Boys/girls (\%/\%) & $44.8 / 55.2$ & $50.8 / 49.2$ & $0.2723^{\mathrm{a}}$ \\
Age, months (mean \pm std. error) & $24.83 \pm 2.331$ & $16.09 \pm 1.65$ & $0.0009^{\mathrm{b}^{*}}$ \\
$\quad$ Birth weight, gr. (mean \pm std. error) & $3,262 \pm 151.5$ & $3,271 \pm 78.78$ & $0.7180^{\mathrm{b}}$ \\
Associated factors & & & \\
Breastfeeding (\%) & 96.50 & 95.40 & $>0.9999^{\mathrm{c}}$ \\
Living with animals (\%) & 55.17 & 73.85 & $0.1201^{\mathrm{a}}$ \\
Kindergarten care (\%) & 41.37 & 16.92 & $0.0108^{\mathrm{a}^{*}}$ \\
$\quad$ Contact with adults with diarrhoea (\%) & 10.34 & 12.3 & $>0.9999^{\mathrm{c}}$ \\
Clinical data & & & \\
Diarrhoea episodes/24 hours (mean \pm std. error) & $7.86 \pm 0.57$ & $6.6 \pm 0.29$ & $0.0375^{\mathrm{b}^{*}}$ \\
Children with fever (\%) & 82.75 & 75.38 & $0.5932^{\mathrm{c}}$ \\
Children with vomit (\%) & 79.31 & 72.30 & $0.472^{\mathrm{a}}$ \\
Clinical dehydration at admittance (\%) & 24.13 & 9.23 & $0.0531^{\mathrm{a}}$ \\
Requires hospitalization (\%) & 13.79 & 3.07 & $0.1967^{\mathrm{c}}$ \\
\hline
\end{tabular}

$P<0.05=$ statistically significant. ${ }^{\text {a }}$ Chi-square test. ${ }^{\mathrm{b}}$ Mann-Whitney test. ${ }^{\mathrm{c}}$ Fisher's exact test 

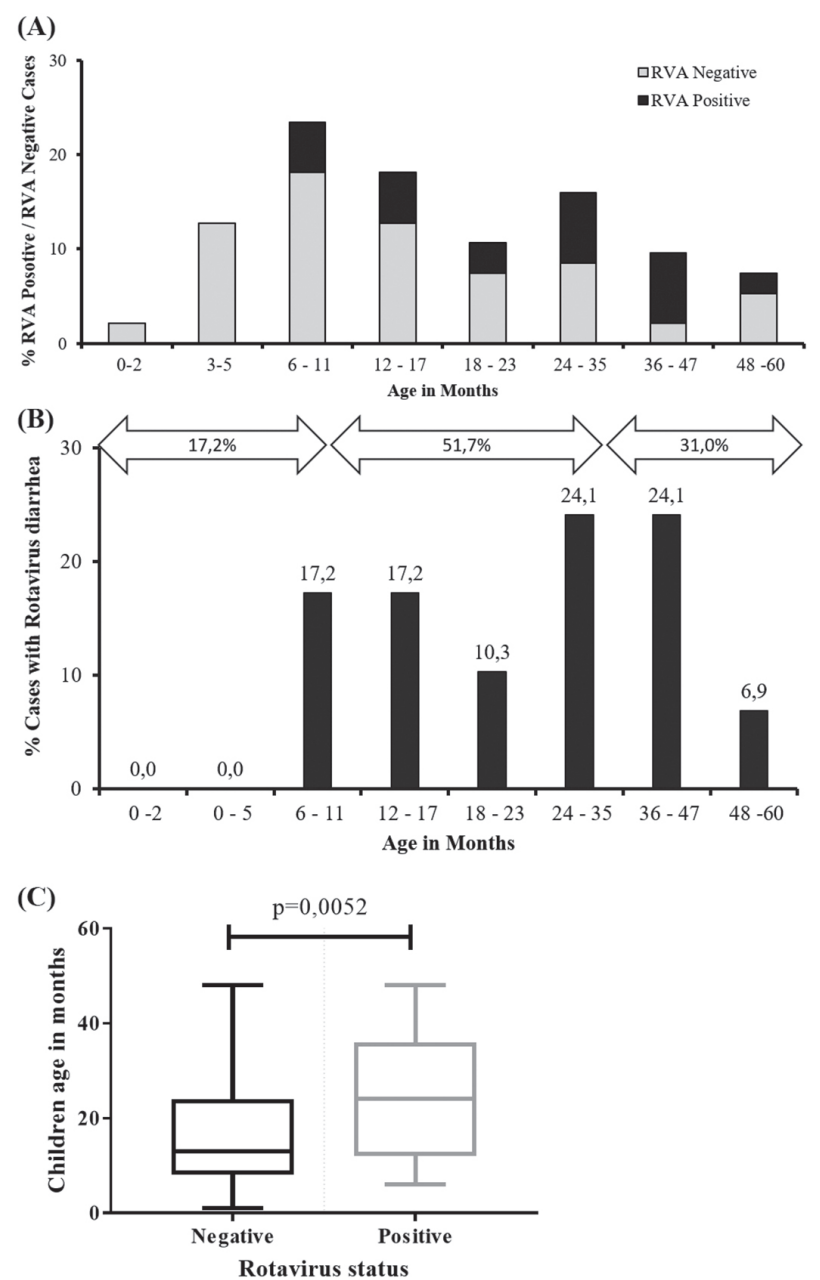

Figure 2 - Age distribution of children under 5 years old. (A) Distribution of rotavirus positive/negative cases by age; (B) Distribution of rotavirus-positive children. The numbers on the bars indicate the exact percentage of patients with rotavirus diarrhoea. The numbers on the arrows indicate the cumulative percentage by age rank; (C) The Tukey box plot shows a comparison between rotavirus-positive and -negative children with respect to age. The $P$ value obtained from the Mann-Whitney test indicates that there is statistical significance.

the $\mathrm{P}$ genotypes, $\mathrm{P}[8]$ was the most prevalent (69\%), followed by $\mathrm{P}[9]$ (31\%). The most common $\mathrm{G}[\mathrm{P}]$ genotype combination was G3P[8] (58.6\%), followed by G3P[9] in $24.1 \%$ of the cases (Table 3 ). The monthly predominance of G3 and P[8] genotypes can be observed in Figures 3A and $3 \mathrm{~B}$, respectively.

\section{DISCUSSION}

Despite the global introduction of vaccines, rotavirus A is still one of the most important causes of acute diarrhoea in most of the world, and the efficacy, safety, and strain-specific effectiveness of the vaccine must be closely monitored in post-licensure surveillance programs.
Table 3 - Distribution of $G$ and $[P]$ genotypes and circulating genotype combinations in children under 5 years old in the Northeastern region of Colombia.

\begin{tabular}{lcc}
\hline \multirow{2}{*}{ Genotype G[P] } & \multicolumn{2}{c}{$\begin{array}{c}\text { \% of cases with the [P] genotype / } \\
\text { (Number of samples) }\end{array}$} \\
\cline { 2 - 3 } & $\mathrm{P}[8]$ & $\mathrm{P}[9]$ \\
\hline G3 & $58.6(17)$ & $24.1(7)$ \\
G3 / G9 & $3.4(1)$ & $0(0)$ \\
G12 & $6.9(2)$ & $6.9(2)$ \\
\hline
\end{tabular}
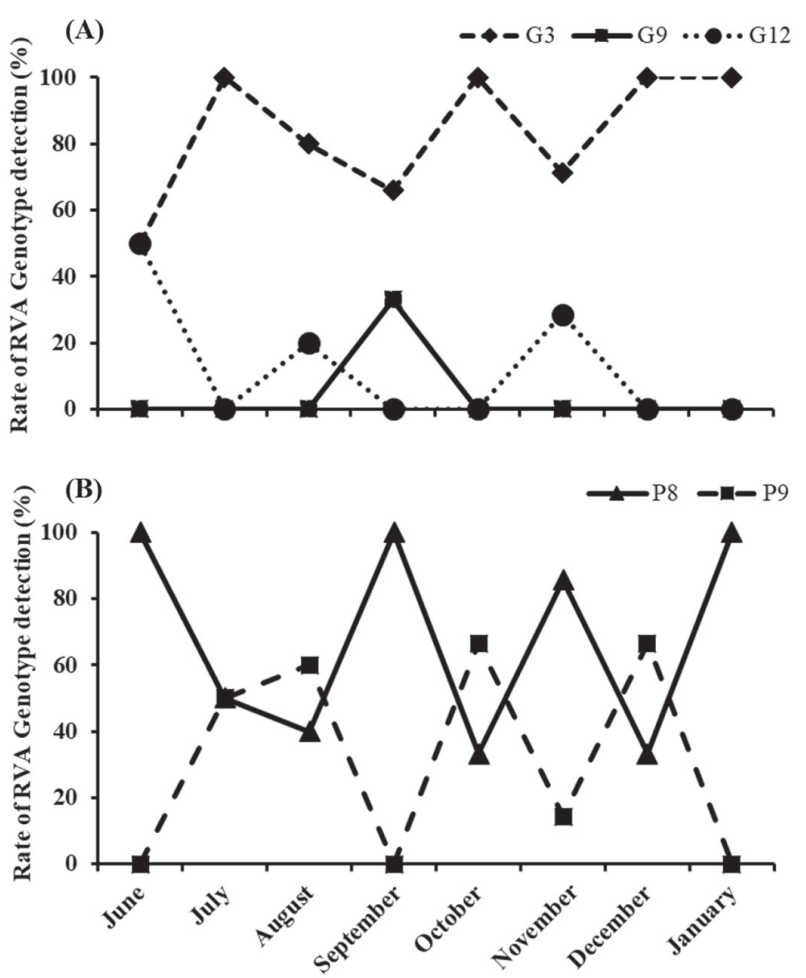

Figure 3 - Monthly rotavirus A genotype confirmation. Genotypes $G(A)$ and $P(B)$ rate distribution are depicted.

The purpose of this study was to determine the presence (prevalence and genotypes) of rotavirus A in children under 5 years of age with acute gastroenteritis in the Northeastern region of Colombia in the post-vaccination era.

Although some countries in the region, such as Mexico, Brazil, Nicaragua, and Panama, have documented substantial decreases of $22-50 \%$ in mortality due to diarrhoea among children under 5 years of age following vaccine introduction $^{16-19}$, a full global declining tendency in the rotavirus burden has not been observed. In fact, recent reports have shown that the predicted annual rotavirus detection rate declined over time from $42.5 \%$ in 2000 to $37.3 \%$ in 2013 , globally ${ }^{7}$. However until the moment, there are no reports about the prevalence of rotavirus in the post-vaccination era in Colombia. Taking into account the 
rotavirus A prevalence found in our study $(30.53 \%, 95 \%$ CI $21.2-39.7 \%$ ) and the few studies reported previously, we can speculate that the vaccination could be reducing the prevalence of the infection in Colombia. However, it is important to mention that the results of this study may not be a true reflection of the rotavirus burden in the Colombian community because the study was conducted with hospital-based samples, and it is well known that rotavirus A-positive cases are usually more severe and likely to be more representative in that type of study.

Before rotavirus vaccination, the National Institute of Health of Colombia (official institution of public health in Colombia) reported that almost $50 \%$ of acute diarrhoea cases in children under five years old could have been caused by rotavirus $\mathrm{A}^{11}$. Studies from other non-official institutions in different Colombian cities had implicated rotavirus $\mathrm{A}$ as the cause of acute diarrhoea in $37 \%-55 \%$ of cases ${ }^{11}$. More recently, in the Northeastern region of Colombia, rotavirus A was found to be the main cause of diarrhoeal disease in children under five years old who consulted emergency services, accounting for $44.4 \%$ of cases $^{20}$.

Our results regarding the vaccine coverage (87\%) fully agree with previous results presented by Cotes $e t$ al. in $2013^{21}$, who reported a coverage with a single dose of the rotavirus vaccine of $87.3 \%$ in a population survey carried out in five Colombian cities (Barranquilla, Bogota, Cali, Cartagena, and Riohacha). The monovalent rotavirus vaccine Rotarix ${ }^{\circledR}$ (GlaxoSmithKline Biologicals, Rixensart, Belgium) was introduced in the Expanded Program on Immunization in January 2009, and the previously mentioned studies were developed over the period from August through October 2010, which could indicate that the vaccine coverage has not increased in five years in the Northeastern region of Colombia, which should be evaluated by official health authorities. Higher rotavirus vaccine coverage could help to accomplish the fourth Millennium Development Goal proposed by the United Nations to reduce mortality by two-thirds in children under 5 years old.

Multiple studies from developed and developing countries suggest that the rotavirus vaccine was effective, based on a $70 \%$ to $100 \%$ reduction in emergency department visits and hospitalizations of children with rotavirus acute gastroenteritis ${ }^{22,23}$. In Colombia, the effectiveness of the rotavirus vaccine in preventing hospitalization due to severe diarrhoea was $68 \%$, and the percentage of hospitalizations due to rotavirus acute diarrhoea was reported to be greater than $5 \%$ 21,24. Our results for the general population studied are close to this percentage (6.7\%); however, in rotaviruspositive children, we observed an important increase in the hospitalization rate, of $14 \%$ (Table 2), which should be assessed in the context of other comorbidities, nutritional status and socioeconomic issues. This clarification is important because malnutrition and a lack of access to appropriate hospital facilities have been reported as the main cause of increased mortality in children from lowincome countries ${ }^{9,10}$

As indicated by our results, rotavirus-associated disease is characterized by fever, diarrhoea and vomiting, which are well known to lead to severe dehydration and increased hospitalization ${ }^{25}$. Rotavirus-positive, compared to -negative diarrhoea cases did not differ significantly when compared according to symptoms such as fever, vomiting or clinical dehydration in children at admission, in our study. However, the presence of these symptoms in diarrhoea cases has been shown to be associated with rotavirus-positivity in a number of studies from other settings ${ }^{26}$, contrary to our current observation. The high number of diarrhoea episodes in rotavirus-positive children (Table 2) increased the risk of dehydration and negative outcomes in the children.

In our region, prior to the rotavirus vaccine introduction, a higher incidence of rotavirus-associated diseases was seen in children between six and twelve months old ${ }^{12}$. Our results show an important increase in the rotavirus age distribution (24.83 \pm 2.331 months, $p=0.0009$ - Figure $2 \mathrm{~A})$. Although this is the first report of this phenomenon in Colombia, indicating a wider burden of rotavirus diseases, changes in the age distribution of children with rotavirus infections have been proposed in different models $^{27}$ and have been reported in clinical studies in different countries ${ }^{28,29}$. In Philadelphia, USA, in 2010, a shift in the positivity to rotavirus infections toward older children was shown after the introduction of the rotavirus vaccine leading to a change in the median age of patients, from 11 months (range, 8-14 months) in 2008 to 23 months in $2009^{28}$. In a similar manner in Belgium, the percentage of all rotavirus A cases reported in children under one year of age declined from $53 \%$ to $26 \%$, and an increase (from $30 \%$ in $2005-2006$ to $40 \%$ in 2008) in children aged 12-23 months was observed ${ }^{29}$. In addition, an increased median age of patients hospitalized due to rotavirus-associated diarrhoea, from 14 months in 2006 to 24 months in 2009, was reported in three US counties ${ }^{30}$. This important result needs to be confirmed by national epidemiological studies to completely understand the role of the rotavirus vaccine in the epidemiological shift of age distribution in infected children. This increase in the age group distribution of rotavirus A infections, has recently been reported in the increasing trend in children aged 25-48 months-old to become infected in Brazil after a decade of the introduction of vaccination with Rotarix ${ }^{\circledR 31}$. 
Due to the highly contagious nature of rotavirus particles, factors that affect the probability of contact with infectious individuals increase the probability of rotavirus infection $^{32}$. Moreover, it is well known that the possibility of rotavirus contaminating objects, toys, and surfaces allows the transmission via fomites ${ }^{33}$. Our results showed that kindergarten care of children is significantly related to rotavirus positivity (Table 2, $p=0.0108$ ). This finding is important for assessing the potential risk of infection in these care facilities and for effectively designing control measures, such as disinfection of surfaces, toys and other objects, as has been recently reported for rotavirus transmission in household contacts of paediatric patients in a USA Surveillance Network that analyzed samples taken between 2011-2016 $6^{34}$.

Although a seasonal trend was reported for G1P[8], $\mathrm{G} 2 \mathrm{P}[4]$ and $\mathrm{G} 3 \mathrm{P}[8]$ rotavirus genotypes previously to the introduction of the vaccine in Colombia ${ }^{11}$, recent analysis has failed to find this pattern ${ }^{20}$. In fact, it has been reported that in tropical countries, rotavirus cases usually occur year-round, although seasonal peaks may occur in winter ${ }^{35}$. Our sampling period included winter seasons in order to include the possible seasonal peak, however this patter was not found in our study.

Our study is the first to describe the different genotypes present in Northeastern Colombia. The G3 genotype has been previously described in other regions of Colombia in a lower ratio ${ }^{20}$ and has been considered as one of the historically well-known endemic strains in combination with $\mathrm{P}[8]$, as we have previously demonstrated ${ }^{36}$. Our results also confirm the presence in Colombia of the emerging G9P[8] and G12P[8] strains which have become globally important ${ }^{36}$ and has been recently denoted as the predominant rotaviruses in the U.S, in spite of $100 \%$ vaccination of children ${ }^{37}$.

It has been postulated that heterotypic strains are being selected by vaccination pressure; however, it has not been established whether these observations are a result of a vaccine-induced immunological pressure or simply reflect natural temporal variations in the circulation of rotavirus genotypes $^{38}$. In 2012, the national laboratory in Colombia reported that G3 genotypes account only for 3.8\% of the total genotypes isolated in the country ${ }^{20}$. Our results show a high proportion of G3P[8] strains (Table 3) that may suggest the potential of strain divergence, as has been previously reported in other Latin American countries ${ }^{39}$ and in Europe ${ }^{40}$. Previous surveillance studies in Colombia did not identify any specific patterns in strain prevalence that support the "strain replacement hypothesis" after the introduction of the monovalent rotavirus vaccine ${ }^{20}$. This result emphasizes the importance of determining the relevance of emergent strains and their relationship to vaccination in broader population and case-control studies.

In conclusion, we used different protocols and laboratory confirmation of rotavirus diarrhoea, including genotyping of rotavirus strains, to shown that rotavirus is still an important pathogen in children under five years old with diarrhoea. The results showed that different factors, such as kindergarten attendance, could explain the rotavirus A epidemiology and transmission in Bucaramanga. The prevalence reported in the study cohort was higher compared to previous reports and the genotyping analysis of the rotavirus A present in our samples indicated the presence of different genotypes, some of them emergent and globally important.

\section{CONFLICT OF INTERESTS}

The authors declare that they have no competing interests.

\section{ACKNOWLEDGMENTS}

The authors thank Liliana Benitez, BSc, for her technical help with the sample collection, and the Bucaramanga Institute of Health - ISABU for allowing us to develop the study.

\section{AUTHORS' CONTRIBUTIONS}

MMG and JRS conceived the study; MMG, VAQ, JTS, and JRS were involved in all other aspects of the study: data collection, data analysis, and drafting and editing the manuscript. All authors read and approved the final manuscript.

\section{REFERENCES}

1. Nguyen TV, Le Van P, Le Huy C, Weintraub A. Diarrhea caused by rotavirus in children less than 5 years of age in Hanoi, Vietnam. J Clin Microbiol. 2004;42:5745-50.

2. Mokomane M, Kasvosve I, Melo E, Pernica JM, Goldfarb DM. The global problem of childhood diarrhoeal diseases: emerging strategies in prevention and management. Ther Adv Infect Dis. 2018;5:29-43.

3. GBD Diarrhoeal Diseases Collaborators. Estimates of global, regional, and national morbidity, mortality, and aetiologies of diarrhoeal diseases: a systematic analysis for the Global Burden of Disease Study 2015. Lancet Infect Dis. 2017;17:909-48.

4. Crawford SE, Ramani S, Tate JE, Parashar UD, Svensson L, Hagbom M, et al. Rotavirus infection. Nat Rev Dis Primers. 2017;3:17083. 
5. Parashar UD, Gibson CJ, Bresse J, Glass RI. Rotavirus and severe childhood diarrhea. Emerg Infect Dis. 2006;12:304-6.

6. World Health Organization. Meeting of the immunization Strategic Advisory Group of Experts, April 2009: conclusions and recommendations. Wkly Epidemiol Rec. 2009;84:220-36.

7. Tate JE, Burton AH, Boschi-Pinto C, Parashar UD, World Health Organization-Coordinated Global Rotavirus Surveillance Network. Global, regional, and national estimates of rotavirus mortality in children $<5$ years of age, 2000-2013. Clin Infect Dis. 2016;62 Suppl 2:S96-105.

8. Troeger C, Khalil IA, Rao PC, Cao S, Blacker BF, Ahmed T, et al. Rotavirus vaccination and the global burden of rotavirus diarrhea among children younger than 5 years. JAMA Pediatr. 2018;172:958-65.

9. Bucardo F, Nordgren J. Impact of vaccination on the molecular epidemiology and evolution of group A rotaviruses in Latin America and factors affecting vaccine efficacy. Infect Genet Evol. 2015;34:106-13.

10. Parashar UD, Johnson H, Steele AD, Tate JE. Health impact of rotavirus vaccination in developing countries: progress and way forward. Clin Infect Dis. 2016;62 Suppl 2:S91-5.

11. Cáceres DC, Peláez D, Sierra N, Estrada E, Sánchez L. La carga de la enfermedad por rotavirus en niños menores de cinco años, Colombia, 2004. Rev Panam Salud Publica. 2006;20:9-21.

12. Uribe Yepes MA, Rodríguez Villamizar LA, Gómez González YA, Olaya Gamboa LE, Rodríguez Santamaría SM. Aislamientos de patógenos comunes asociados con enfermedad diarreica aguda en menores de cinco años, Bucaramanga, Colombia. MedUNAB. 2009;12:72-9.

13. World Health Organization. Manual of rotavirus detection and characterization methods. Geneva: WHO; 2009.

14. Gouvea V, Glass RI, Woods P, Taniguchi K, Clark HF, Forrester $\mathrm{B}$, et al. Polymerase chain reaction amplification and typing of rotavirus nucleic acid from stool specimens. J Clin Microbiol. 1990;28:276-82.

15. World Health Organization. The treatment of diarrhoea: a manual for physicians and other senior health workers. $4^{\text {th }}$ ed. Geneva: WHO; 2005.

16. Richardson V, Hernandez-Pichardo J, Quintanar-Solares M, Esparza-Aguilar M, Johnson B, Gomez-Altamirano CM, et al. Effect of rotavirus vaccination on death from childhood diarrhea in Mexico. N Engl J Med. 2010;362:299-305.

17. Carmo GM, Yen C, Cortes J, Siqueira AA, Oliveira WK, CortezEscalante JJ, et al. Decline in diarrhea mortality and admissions after routine childhood rotavirus immunization in Brazil: a time-series analysis. PLoS Med. 2011;8:e1001024.

18. Bayard V, DeAntonio R, Contreras R, Tinajero O, Castrejon $\mathrm{MM}$, Ortega-Barria E, et al. Impact of rotavirus vaccination on childhood gastroenteritis-related mortality and hospital discharges in Panama. Int J Infect Dis. 2012;16:e94-8.

19. Mast TC, Khawaja S, Espinoza F, Paniagua M, Del Carmen LP,
Cardellino A, et al. Case-control study of the effectiveness of vaccination with pentavalent rotavirus vaccine in Nicaragua. Pediatr Infect Dis J. 2011;30:e209-15.

20. Peláez-Carvajal D, Cotes-Cantillo K, Paternina-Caicedo A, Gentsch J, de la Hoz-Restrepo F, Patel M. Characterization of rotavirus genotypes before and after the introduction of a monovalent rotavirus vaccine in Colombia. J Med Virol. 2014;86:1083-6.

21. Cotes K, Alvis-Guzmán N, Rico A, Porras A, Cediel N, Chocontá Piraquive LA, et al. Evaluación del impacto de la vacuna contra rotavirus en Colombia usando métodos rápidos de evaluación. Rev Panam Salud Publica. 2013;34:220-6.

22. Linhares AC, Velázquez FR, Pérez-Schael I, Sáez-Llorens X, Abate H, Espinoza F, et al. Efficacy and safety of an oral live attenuated human rotavirus vaccine against rotavirus gastroenteritis during the first 2 years of life in Latin American infants: a randomised, double-blind, placebo-controlled phase III study. Lancet. 2008;371:1181-9.

23. Vesikari T, Karvonen A, Prymula R, Schuster V, Tejedor JC, Cohen $\mathrm{R}$, et al. Efficacy of human rotavirus vaccine against rotavirus gastroenteritis during the first 2 years of life in European infants: randomised, double-blind controlled study. Lancet. 2007;370:1757-63.

24. Cotes-Cantillo K, Paternina-Caicedo A, Coronell-Rodríguez W, Alvis-Guzmán N, Parashar UD, Patel M, et al. Effectiveness of the monovalent rotavirus vaccine in Colombia: a case-control study. Vaccine. 2014;32:3035-40.

25. Glass RI, Kilgore PE, Holman RC, Jin S, Smith JC, Woods PA, et al. The epidemiology of rotavirus diarrhea in the United States: surveillance and estimates of disease burden. J Infect Dis. 1996;174 Suppl 1:S5-11.

26. Rodriguez WJ, Kim HW, Brandt CD, Schwartz RH, Gardner MK, Jeffries B, et al. Longitudinal study of rotavirus infection and gastroenteritis in families served by a pediatric medical practice: clinical and epidemiologic observations. Pediatr Infect Dis J. 1987;6:170-6.

27. Pitzer VE, Viboud C, Simonsen L, Steiner C, Panozzo CA, Alonso WJ, et al. Demographic variability, vaccination, and the spatiotemporal dynamics of rotavirus epidemics. Science. 2009;325:290-4.

28. Clark HF, Lawley D, Matthijnssens J, DiNubile MJ, Hodinka RL. Sustained decline in cases of rotavirus gastroenteritis presenting to the Children's Hospital of Philadelphia in the new rotavirus vaccine era. Pediatr Infect Dis J. 2010;29:699-702.

29. Hanquet G, Ducoffre G, Vergison A, Neels P, Sabbe M, Van Damme P, et al. Impact of rotavirus vaccination on laboratory confirmed cases in Belgium. Vaccine. 2011;29:4698-703.

30. Payne DC, Staat MA, Edwards KM, Szilagyi PG, Weinberg GA, Hall CB, et al. Direct and indirect effects of rotavirus vaccination upon childhood hospitalizations in 3 US counties, 2006-2009. Clin Infect Dis. 2011;53:245-53. 
31. Carvalho-Costa FA, Assis RM, Fialho AM, Araújo IT, Silva MF, Gomez MM, et al. The evolving epidemiology of rotavirus A infection in Brazil a decade after the introduction of universal vaccination with Rotarix ${ }^{\circledR}$. BMC Pediatr. 2019;19:42.

32. Phillips G, Lopman B, Rodrigues LC, Tam CC. Asymptomatic rotavirus infections in England: prevalence, characteristics, and risk factors. Am J Epidemiol. 2010;171:1023-30.

33. Raebel MA, Ou BS. Rotavirus disease and its prevention in infants and children. Pharmacotherapy. 1999;19:1279-95.

34. Wikswo ME, Parashar UD, Lopman B, Selvarangan R, Harrison $\mathrm{CJ}$, Azimi PH, et al. Evidence for household transmission of rotavirus in the United States, 2011-2016. J Pediatric Infect Dis Soc. In Press 2019.

35. Pan American Health Organization. Epidemiological surveillance of diarrheal diseases due to rotavirus: field guide. Washington: PAHO; 2010

36. Dóró R, László B, Martella V, Leshem E, Gentsch J, Parashar U, et al. Review of global rotavirus strain prevalence data from six years post vaccine licensure surveillance: is there evidence of strain selection from vaccine pressure? Infect Genet Evol. 2014;28:446-61.

37. Ogden KM, Tan Y, Akopov A, Stewart LS, McHenry R, Fonnesbeck CJ, et al. Multiple introductions and antigenic mismatch with vaccines may contribute to increased predominance of G12P [8] rotaviruses in the United States. J Virol. 2018;93:e01476-18.

38. Mameli C, Fabiano V, Zuccotti GV. New insights into rotavirus vaccines. Hum Vaccin Immunother. 2012;8:1022-8.

39. Romero C, Mamani N, Halvorsen K, Iñiguez V. Enfermedades diarreicas agudas asociadas a rotavirus. Rev Chil Pediatr. 2007;78:549-58.

40. Zuccotti G, Meneghin F, Dilillo D, Romanò L, Bottone R, Mantegazza C, et al. Epidemiological and clinical features of rotavirus among children younger than 5 years of age hospitalized with acute gastroenteritis in Northern Italy. BMC Infect Dis. 2010;10:218. 